\title{
La producción del espacio social en la Amazonía brasileña a través de las represas hidroeléctricas: El caso del conflicto de Belo Monte
}

\author{
Ismael De La Villa Hervás*
}

\begin{abstract}
RESUMEN
Durante las últimas décadas en Brasil se ha producido un incremento significativo de los conflictos hidrosociales a causa de la construcción de grandes complejos hidroeléctricos. Esta extensión de grandes proyectos de carácter extractivista en la región amazónica, sobre todo a partir de finales de la década de los años ochenta del siglo pasado, han conllevado todo un conjunto de transformaciones en las relaciones sociales, productivas y reproductivas, de cara avanzar en mecanismos para la integración regional y nacional, así como para la superación de crisis de acumulación propias de la escala global. Entre todos, por su trascendencia y dilatación en el tiempo, probablemente el que más destaca es el de la represa de Belo Monte en el río Xingú, próximo a la ciudad de Altamira. En él se ven involucrados una multiplicidad de actores (comunidades indígenas, campesinos, pescadores, el estado, Eletrobras, constructoras, instituciones supranacionales, etc) cuya disputa por el acceso a los recursos hídricos supone una modificación de la configuración de las relaciones de poder que se dan en el territorio. Este artículo, además de analizar el recorrido espacio-temporal de dicho conflicto, se propone dos objetivos adicionales. Por un lado la elaboración de un marco teórico, que conjugue las perspectivas de la producción de la naturaleza, la producción del espacio y la construcción de la escala, que pueda ser aplicado al análisis de conflictos ambientales que tienen lugar en el Sur Global. Por otro lado, y en consecuencia, a través de su empleo en el estudio de este caso particular, determinar las fortalezas y debilidades que presenta para su uso en futuros trabajos similares. De cara a ello se plantea una metodología basada en la revisión bibliográfica y el uso tanto de fuentes primarias como secundarias, mediante las cuales se puedan extraer y analizar el conjunto de prácticas, representaciones y relaciones que dan forma al conflicto en sí mismo. A su vez, el artículo se divide en cuatro partes principales: el planteamiento de articulación entre las distintas categorías y aspectos de los planteamientos teóricos para su uso en el estudio de caso; el análisis del desarrollo espacio-temporal del conflicto, desde el inicio de la planificación del proyecto hasta día de hoy; en tercer lugar se explica y detalla el papel de los actores hegemónicos en el avance de la construcción del complejo hidroeléctrico; y en última instancia se lleva a cabo la misma operación pero con los actores subalternos implicados. De entre los resultados obtenidos, destaca cómo este proyecto a nivel particular, y los macroproyectos hidroeléctricos en general en la región, han sido fundamentales para la integración económica en el marco de la extensión de las relaciones de producción capitalistas y los mecanismos para la acumulación a través de la realización del plusvalor, derivando resistencias ante este proceso de extracción. Así mismo, la perspectiva interescalar y la de la producción del espacio muestran potencialidades como marco para el estudio de conflictos ambientales, mientras que el de la producción de la naturaleza lo hace de manera parcial.
\end{abstract}

\section{Palabras clave}

Belo Monte; conflicto hidrosocial; represas; producción de la naturaleza; espacio social.

\section{Tithe}

The production of social space in Brazilian Amazon through hydroelectric dams: The case of Belo Monte's conflict

\section{Abstract}

During the last decades in Brazil there has been a significant increase in hydrosocial conflicts due to the construction of large hydroelectric complexes, which involve qualitative and quantitative changes regarding access and ownership of water. It
* Ismael DE LA VILLA HERVÁS, Graduado en Biotecnología, Ciencias Políticas y Máster en Comunicación Política.

Actualmente es doctorando en Ciencias Políticas y Relaciones Internacionales en la Universidad Complutense de Madrid. Contacto: ismadela@ucm.es

Recibido:

09/12/2019

Aceptado:

13/09/2020

\section{DOI:}

https://doi.org//0.15366/relacionesinternacionales2020.45.008

Formato de citación recomendado:

DE LA VILLA HERVÁS, Ismael (2020). "La producción del espacio social en la Amazonía brasileña a través de las represas hidroeléctricas: El caso del conflicto de Belo Monte”, Relaciones Internacionales, n 45, pp. I85-204. 
has opened a new period of accumulation and transformation of production relations through the commodification of this important resource. This has seen the extension of large projects of an extractivist nature in the Amazon region, especially from the end of the eighties of last century, after the settlement of the so-called Washington consensus. This phenomenon led to a whole series of transformations in productive, reproductive and social relations, in order to provide mechanisms for regional and national integration, as well as for overcoming accumulation crises emanating from the global scale. In the Brazilian case, these reforms undertaken in recent decades in the political, social, environmental, economic and legislative realms, have not meant a major change in the productive level of the world-economy scale, since the peripheral role of the country, initiated during the colonial period, is still maintained. But they have deepened their dependence through the extractivist development model, highlighting among other practices (such as the advance of the agricultural frontier, large soybean crops, the deployment of fracking to increase income derived from hydrocarbons, etc. .) the large hydroelectric complexes located throughout the country's vast hydrographic basin. The main goal of this kind of new structure is to produce higher levels of energy, largely dedicated to the processing of aluminium, whose demand has increased exponentially in recent years in states such as China, among other members of BRICS

From all these hydroelectric structures, probably the one that stands out the most is the Belo Monte dam on the Xingú river, near to the city of Altamira, due it its importance and expansion over time. A multiplicity of actors are involved in this one (indigenous communities, fishing farmers, the State, Eletrobras, non-governmental organizations, indigenous confederations, construction companies, supranational institutions, etc.), and whose dispute over access to water resources implies a modification of the configuration of the power relations that take place in the territory. In spite of the fact that its planning began in 1975, within the framework of the search for a better use of the country's hydroelectric potential and to boost economic development and energy sovereignty, the advances and setbacks in the settlement of the operation of the infrastructure have been delayed until today and probably will continue in the near future. This paper not only aims to analyze the spatio-temporal path of this controversial conflict, but proposes two additional objectives. On the one hand, the elaboration of a theoretical framework that combines the perspectives of the production of nature, the production of space and the construction of scale, which could be applied to the analysis of other environmental conflicts that take place in the global south. On the other hand, and as a consequence of its use in this particular case, it seeks to determine the strengths and weaknesses of this theoretical framework for future similar work. Hitherto the majority of the works and papers related to this case study are focused on the contentious politics of social movements and communities to stop the development of the project.A significant number also analyze the contradictions of PT through the Brazilian state regarding the different social impacts of the dam. This article aims to go further and provide tools and categories to explain the practices, relations and structures which are involved this process.

In view of this, a methodology based on bibliographic review, and the use of both primary and secondary sources is proposed. Through this method, it is possible to outline the set of practices, representations and relationships that shape the conflict itself. In turn, to achieve this end, the article is divided into four main parts. In the first, an articulation approach is developed between the different categories and aspects of the theoretical gazes for their uses in the case study. In relation with the perspective of the production of nature, originally developed by Neil Smith, the categories of use value and exchange value are fundamental. These, through their dialectic within relations of production, modify through the passing of time the metabolism that takes place between nature and society itself, generating conflicts where these changes imply a clash between two modes of production. With this fact different values prevail over the environmental resources, whose access is sought to continue the process of social reproduction. In addition to this, the proposed framework take in count the categories of spatial practices, representations of space and spaces of representation, formulated by Henri Lefebvre, in order to explain how changes in power relations involve changes in the space in which they are inserted and vice versa. Furthermore, with the interscalar perspective proposed by several scholars that are mentioned, the possibility of explaining how phenomena and actors from different scales influence the local one during the long development of the conflict. Subsequently, in the second section of the paper, the analysis of the spatio-temporal development of the conflict is carried out, from the beginning of project planning, through the modifications carried out by the different governments, the changes in the positions of the actors, the different law resolutions, the granting of licenses and so on, until today.

Thirdly, the role of hegemonic actors in advancing the construction of the hydroelectric complex is explained and detailed, for which it is not only important to analyze the different representations and narratives carried out by different governments with respect to the project of Belo Monte, but also how state hydroelectric companies (Eletrobras and Eletronorte) are affected by the entrance of foreign capital, changing over time the spatial practices that are carried out, as well as the different positions of the institution responsible for the granting of environmental licenses to allow the dam activity (IBAMA).At the end, in the last part, the same operation is made but with the subordinate actors involved, which basically would be the local and foreign non-governmental organizations, as well as the communities of indigenous, peasant and fishermen of the locality. For them, the river fundamentally supposes a use value insofar as it is used as a source of resources and transportation to maintain pre-capitalist production relations on which they are sustained. Obviously these activities have a low exchange value produced through its limited technology to harvesting and fishing, that finally are destined for local trade.

The main results which can be highlighted are related with how this dam in particular, and the different hydroelectric projects in general along the region, allow to extend spatially an economic integration through the deployment of new relations of production and mechanisms for accumulation. These ones suppose an appearance of new use values, exchange values and values that clash against the previous ones thus producing the social struggle in the local scale around the dam. Furthermore, the frameworks of the scale and the production of social space show as useful theories for its application to future cases of environmental conflicts, meanwhile the production of nature framework shows some difficulties in order to use some of its categories for the case study.

\section{KEYWORDS}

Belo Monte; hydrosocial conflict; dams; production of nature; social space. 


\section{ntroducción}

Durante las últimas décadas se ha podido observar cómo Brasil ha experimentado un proceso histórico mediante el cual su economía ha aumentado la dependencia con respecto a actividades relacionadas con la recolección de maderas, los cultivos de soja, la ganadería bovina a gran escala y la producción de energía eléctrica a través de la construcción de grandes represas (Dos Santos y Milanez, 20I3). Esta última ha sido la que más ha proliferado con diferencia, dando lugar a toda una serie de conflictos socioambientales que convierten a Brasil en el segundo país del mundo en este aspecto'. Este fenómeno sólo puede comprenderse si desde la escala nacional se da un paso más allá y se toma una perspectiva global que tenga en cuenta cómo tras la crisis de acumulación, que tuvo lugar a finales de los años setenta del siglo $X X$, se llevaron a cabo en la práctica totalidad de estados del mundo, una serie de liberalizaciones de sectores económicos y reformas legislativas en materia política, laboral y tributaria, así como una modificación de los tipos de cambio derivados de las instituciones del pacto de Bretton Woods (Harvey, 2007a). Este conjunto de transformaciones experimentadas, se denominaron como los Consensos de Washington (Williamson, 1993) dotando así al estado-nación de un rol distinto, con respecto al adquirido tras la Segunda Guerra Mundial.

Este proceso ha alterado tanto el Norte y el Sur Global, pero con distintas consecuencias en cada uno de ellos. El primero se ha reconfigurado a través del consenso de las commodities (Svampa, 2013), reforzando su papel extractivista, aumentando estas prácticas y su dependencia externa con respecto a ellas. En cualquier caso, no habría supuesto una alteración radical de la posición del Sur Global en la estructura productiva de la economía-mundo, sino que se trataría de una profundización de su carácter extractivista y periférico ya previo (Frank, 1972). En Brasil, en relación a las represas, con dos fines: el semiprocesado del aluminio, ya que es una materia prima que requiere de un tratamiento que consume una importante cantidad de energía eléctrica y la experimentación de transformaciones espaciales, como un avance progresivo del proceso de urbanización, desplazando a las ciudades a múltiples capas de la población, derivando en un mayor consumo energético (Arboleda, 2016).

Así, Brasil en el 2016 se convirtió en un estado en el cual más del $65 \%$ de la energía eléctrica que se genera procede de las centrales hidroeléctricas ${ }^{2}$. Aunque determinados sectores defienden este tipo de proyectos, basándose en su escasa contaminación directa y su bajo coste de producción, existen otros que se oponen alegando los numerosos impactos ambientales y sociales que llevan asociados, como la desaparición de las comunidades que habitan el territorio en cuestión, la contaminación de manera indirecta y la pérdida de biodiversidad entre otros (Kingsford, 2000). Es a través de este antagonismo derivado del apoyo o la resistencia a la construcción de estas infraestructuras, como emergen los conflictos hidrosociales (Swyngedouw et al., 2009).Van más allá de las meras interacciones de unión y antagonismo que se dan de manera inherente en todo tipo de estructura social (Simmel, 20l0). Los conflictos hidrosociales emergen como reflejo de las transformaciones que tienen lugar en un territorio a raíz de la consolidación de nuevas prácticas y estructuras para el acceso a un recurso como el agua reaccionando mediante la contestación y la disputa por parte de los actores implicados (Swyngedouw, 2009; Hommes, Boelens y Maat,

Datos del Observatorio de Justicia Ambiental. Recuperado de: ejatlas.org/country (0I/I2/20 I9).

Dato procedente de la web de la Agencia Internacional de la Energía. Recuperado de: https:/www.iea.org/data-andstatistics?country=BRAZIL\&fuel=Energy\%20supply\&indicator=Electricity\%20generation\%20by\%20source (0I/I2/2019). 
2016). En base a ello podrían diferenciarse cuatro grandes tipos de conflictos hidrosociales, a lo largo de la historia en función de qué cambios en las relaciones sociales y productivas tuvieron lugar (Kaika, Swyngedouw y Castro, 2002); el de la distribución de agua potable como bien privado durante el auge de la burguesía como clase social dominante, la municipalización del agua en las grandes ciudades industriales como mecanismo para la reproducción de la fuerza de trabajo, el agua como elemento para la creación de grandes infraestructuras (presas, canales, grandes sistemas de riego) empleadas para la expansión económica tras la crisis de 1929 y en último lugar el ciclo del agua para su privatización (en gestión, propiedad o en ambas) como respuesta a la crisis de acumulación capitalista tras 1973. Este estudio de caso se ubicaría dentro del último ciclo, lo cual hace necesario tener en cuenta la dimensión espacial global que adquieren estos conflictos (Warner, 2008).

Existe una amplia y reciente bibliografía que recoge los últimos cambios acaecidos en relación con este conflicto. En ella, destacan sobre todo los trabajos que abordan esta temática desde la perspectiva de la acción colectiva de los actores afectados desplegando prácticas y movilizaciones frente al estado (Fleury, 20I4; Klein, 20I5; Peters, 20I7; Ramos y Alves, 20I8), los análisis críticos de las políticas públicas medioambientales entorno al proceso de construcción de la presa (Fearnside, 2016; Issberner y Léna, 2017), de las contradicciones del PT con el proyecto tras acceder al gobierno (Pase et al, 2016; Fearnside, 2017), del análisis de la construcción de la represa en el contexto del neodesarrollismo del siglo XXI (Correa, 2016), desde el punto de vista de las políticas ambientales en el nuevo marco jurídico (Faingelernt, 20/3), desde el análisis crítico de discurso de los distintos actores implicados (Riethof, 20I7), así como desde el estudio del conflicto a partir las políticas para el desarrollo rural local de Belo Monte (Randell, 2016). Pese a esta variedad, la mayor parte de esta producción académica adopta sobre todo un enfoque comprensivo del conflicto, se focaliza en la escala nacional como marco preferente, presta más atención a las contradicciones del PT dentro del estado más que en posibles explicaciones de sus prácticas, así como predomina un marco teórico como es el del contentious politics y la teoría de la elección racional.

El estudio de caso del conflicto hidrosocial de Belo Monte, puede resultar de gran utilidad para responder distintas cuestiones que son de interés para la Ecología Política, siempre y cuando se introduzcan nuevas variables y enfoques distintos a los predominantes hasta ahora. Este trabajo presenta tres objetivos para posibilitarlo. Primero, realizar una propuesta de marco teórico que aúne la teoría de la producción de la naturaleza, la del espacio e incorpore la perspectiva de la escala al análisis. El segundo objetivo, mediante las categorías propuestas, es estudiar el conflicto el conflicto de Belo Monte con el fin de proporcionar una explicación y comprensión de todo el proceso. El último de todos sería en consecuencia determinar si a través de los resultados obtenidos, el marco propuesto resulta de utilidad para el estudio de otros conflictos derivados de proyectos similares en el Sur Global. Para ello, el texto se estructura en tres apartados: en el primero se detallan las herramientas epistemológicas que servirán de prisma para el análisis; en el segundo, se lleva a cabo el estudio del caso, dividiéndolo en tres subapartados que encuentran su justificación en el apartado del marco teórico. Por último, a modo de conclusión, se recogen las principales ideas plasmadas a lo largo del texto, sometiéndolas a una valoración de la trascendencia que puedan llevar consigo. En definitiva, este artículo busca una realizar una aportación original con nuevos elementos como la interescalaridad del conflicto en el contexto del ciclo de las commodities; 
analizar el papel del estado en la extensión de las relaciones de producción y los mecanismos de acumulación a través del complejo hidroeléctrico; así como las resistencias y prácticas del resto de actores implicados desde una perspectiva materialista, que hasta ahora no ha predominado como marco de análisis para el caso.

En cuanto a la metodología para conseguir dichos objetivos, se han desarrollado múltiples en distintos trabajos, desde prismas más cuantitativos o cualitativos (Dutt y Krishna, 1990; Heynen, Perkins y Roy, 2006), así como otras focalizadas en los aspectos de las relaciones productivas o en los de las medioambientales (Briassoulis, 2019). Para este caso se propone tanto el empleo de bibliografía previa que recoja el desarrollo del conflicto, así como fuentes tanto primarias como secundarias (documentos jurídicos, planes institucionales, declaraciones, entrevistas en medios etc.) para recopilar el conjunto de prácticas, discursos y cambios sociales que acontecen. El trabajo se desarrolla fundamentalmente en el plano cualitativo, ya que, si bien el enfoque adoptado es interescalar, al ser un estudio de caso tan concreto, la escala local gana especial relevancia, aunque se interrelacione con las superiores, dificultando la aplicación de metodologías más cuantitativas y adaptadas a niveles espaciales superiores, que desplazarían el marco de la Ecología Política por el de la Economía Ecológica (Martínez Alier y Jusmet, 20I5). Lo cual no implica que no se pierda de vista que la dimensión de la producción es indisociable de la medioambiental.

\section{La producción de la naturaleza, del espacio y la escala como herramientas de aná- lisis}

Gran parte de los enfoques en la Ecología Política, surgen de la premisa iniciada en la escuela de Berkeley por Carl Sauer, mediante la cual naturaleza y sociedad son dos esferas claramente diferenciadas.A partir de ahí, el estudio de la relación entre ambas se dotó de premisas fuertemente malthusianas y antropologicistas, que terminaban derivando en explicaciones muy marcadas por ideas como la de la adaptación al medio, la superación de los periodos de escasez y una mirada a cada entorno natural como sistemas aislados y cerrados espacialmente (Watts, 2015). Esta demarcación dentro de la Ecología Política ha permanecido presente hasta día de hoy, bien entre corrientes en los que predominaban enfoques más ecocentristas (Daly, 1989; McKibben, 1989) o más antropocentristas (Redclift, 1991; Simon, 1992).

Opuesta a esta concepción formal, que asume la existencia per se de una naturaleza divorciada de la sociedad, surge en los años setenta una nueva, fruto de la revisión de los trabajos de Karl Marx y Friedrich Engels acerca de la naturaleza (Schmidt, 2013) que derivará en los primeros trabajos críticos de Ecología Política (Peet y Watts, 2004) guiados por una mirada materialista. Tomando esta base, Neil Smith (2010) será el primero que se encargue de elaborar un nuevo enfoque dialéctico, recogido en su principal obra: La producción de la naturaleza. Su tesis central pivota entorno a la categoría de metabolismo social, según la cual el ser humano a lo largo de la historia habría empleado su fuerza de trabajo, para obtener mediante los medios de producción que posee, una serie de valores de uso de la naturaleza que permitieran llevar a cabo su reproducción social. De cara a perpetuarla, se establecerían una serie de divisiones sociales del trabajo, sostenidas por un conjunto de dispositivos y superestructuras, que darían lugar a un reparto desigual de estos medios de producción, los cuales a medida que se vayan desarrollando y se apoyen en tecnologías más avanzadas, alterarán las relaciones sociales, y por 
tanto las necesidades sociales a satisfacer a través de los valores de uso de la transformación de la naturaleza.

Esta dialéctica, que sólo entiende una categoría en una relación de negación con respecto a la otra, es la producción de la naturaleza. En concreto, bajo el modo de producción capitalista, transforma los productos obtenidos en mercancías, y por tanto, además de poseer un carácter cualitativo (valor de uso) son intercambiables por semejantes, adquiriendo carácter cuantitativo (valor de cambio). La clave por tanto dentro del marco de la producción de la naturaleza es la práctica, la cual cuestiona conceptos que se basan en la dependencia de la sociedad con respecto a la naturaleza en términos demográficos. No obstante, esto no quiere decir que esta concepción materialista de la naturaleza deba dejar a un lado los impactos que esta puede tener a partir de los límites biofísicos por los cuales se ve afectada, tal y como apuntan algunos autores dentro de esta corriente (Hughes, 2000; Altvater, 2006), deben tenerse en cuenta, por su importancia en la modelación de este vínculo.

Sin embargo, para el asentamiento de los nexos teóricos en este vínculo ecosocial, emerge una disyuntiva, que debe de ser analizada dentro de este trabajo, a través de la aplicación de los distintos enfoques que dos de sus ramas ofrecen dentro de esta epistemología. Por un lado, el que parte de la idea de naturaleza como un elemento más de las condiciones externas ${ }^{3}\left(\mathrm{O}^{\prime}\right.$ Connor, 200I). Junto a la fuerza de trabajo y a la superestructura, la naturaleza, en tanto que se trata de condiciones físicas que influyen de manera directa sobre el modo de producción, se encontraría dentro de este conjunto. Las crisis de subproducción derivadas de estas condiciones externas, son las que motivarían un avance en esa producción de la naturaleza.

Fenómenos climáticos como la acidificación del agua dulce, la desertificación de los bosques, el deshielo de los casquetes polares y el aumento de la temperatura media global, los cuales ponen en riesgo la producción agrícola a gran escala y el acceso a recursos energéticos, incentivan una acción de los estados y las instituciones supranacionales dirigida a una mayor integración dentro de las relaciones del modo de producción. De ahí un aumento de la legislación y el control con respecto a las especies en peligro de extinción, la emisión de gases de efecto invernadero, el desarrollo de organismos modificados genéticamente, el número de áreas protegidas, la financiación de proyectos tecnológicos para la mitigación y adaptación al cambio climático, etc. (Moore, 20I I). Todo de cara a ampliar la realización del plusvalor durante estas crisis de subproducción. Mientras, por otro lado, frente a este concepto de condiciones externas para la producción de la naturaleza, está el de la primera y la segunda naturaleza (Castree, 2005).

En la primera naturaleza, no existe una demarcación tan clara entre la naturaleza humana y no humana en términos de trabajo. A medida que más median las divisiones sociales del trabajo en el acceso a la naturaleza, más prima el valor de cambio en tanto que está más insertado en otro modo de producción. Lo que se obtiene del trabajo solo es una fracción del valor de cambio final. La otra fracción (el plusvalor) se realiza bajo la forma de medios de producción, para generar más valor de cambio y una mayor acumulación; alejándose de formas de coerción política e insertándose en aquellas de extracción económica (Burkett, 20I3). Incluso la naturaleza, como

Frente a los medios de producción y las relaciones productivas como condiciones internas, $\mathrm{O}^{\prime}$ Connor identifica a la naturaleza no humana, la fuerza de trabajo y la superestructura como condiciones externas al modo de producción. 
patrimonio natural, como objeto externo a la sociedad a ser protegido de manera ideológica, se convierte en valor de uso y se media a través del valor de cambio, como ocurre con las reservas naturales, las especies protegidas, los derechos de tercera generación etc. De esa forma, se avanza hacia una segunda naturaleza. No como departamentos estancos sino como procesos sociales. En este caso, no se hace necesaria una crisis de subproducción para la producción de naturaleza, sino que se da de una manera no mecánica a nivel histórico y espacial (Castree, 2008; Loftus y Eker, 20I3).

Partiendo de aquí, es necesario tener en cuenta el espacio dentro de los estudios de Ecología Política. Esto se debe a que las relaciones de poder que emergen bajo unos conflictos determinados, no sólo deben de ser analizadas en el plano diacrónico, ya que también poseen un correlato diatópico, aunque tradicionalmente en el pensamiento moderno el espacio haya estado subordinado al tiempo (Soja, 1989). Henri Lefebvre (1991), propone una mirada relacional para entender los cambios que acontecen en el espacio, superando así su concepción estática. Según su propuesta, el espacio social vendría a ser producto de las transformaciones acontecidas en las relaciones que lo constituyen. Al ser relaciones de poder, convierten todo espacio en un elemento político. Su reconfiguración, no se puede entender de manera formal, si no debe de hacerse a través de una dialéctica con el elemento temporal.Aunque esta dialéctica, para Lefebvre, no se da tanto en un modo hegeliano lineal, de superación de todas las contradicciones entre ambas partes mediante una síntesis, sino que se avanza a un estadio superior constituido sobre esas mismas contradicciones (Shields, 2005).

Lefebvre elabora un conjunto de categorías para analizar los procesos de producción del espacio social. Formula tres conceptos centrales, que estarían en una continua interacción, dando sinergias o contradicción, generando un espacio concreto: las prácticas espaciales, las representaciones del espacio y los espacios de representación. Las primeras vendrían a ser el espacio percibido, todas aquellas acciones que se llevan a cabo sobre la realidad para hacer efectiva la reproducción de las relaciones sociales que lo constituyen, como pueden ser las formas de movilidad, las distribuciones urbanas y rurales, el desarrollo de determinadas infraestructuras etc. Se trataría de la incorporación de la perspectiva material del espacio, como crítica al idealismo que ve en la dialéctica hegeliana. Mientras, las representaciones del espacio abarcarían la dimensión concebida del espacio, y por tanto todas aquellas imágenes, teorías espaciales y construcciones mentales que se elaboran desde posiciones de dominio (diseñadores de políticas públicas, urbanistas, geógrafos) y que luego se aplican sobre la realidad. Por último, los espacios de representación, como parte vivida del espacio,y todo aquello relacionado con cómo se reproducen o se subvierten las prácticas espaciales hegemónicas, pero desde posiciones subalternas. Pueden ser de un carácter contrahegemónico a lo ingeniado por los planificadores espaciales o pueden dar continuidad al simbolismo otorgado al espacio ya producido previamente (Lefebvre, 199I).

Para completar el marco teórico, es necesario incorporar una mirada no sólo horizontal del espacio, sino también vertical,y por lo tanto escalar. En su origen, la primera propuesta metodológica para el análisis de la escala (Taylor, 1982) se basó en una clara separación entre la escala local o de la experiencia, la estatal o de la ideología y la global o la de la realidad. Posteriormente se empezó a conceptualizar la escala como una dimensión que también es producida (Kelly, 1999; Marston, 2000). Como categoría constituida a través de procesos, la escala no puede entenderse como 
algo preestablecido y fijo, sino como una red en continua reconfiguración a través de distintos conflictos políticos y alteraciones de las relaciones de poder (Swyngedouw y Heynen, 2003). Los distintos cambios en los procesos de acumulación, de flujos del capital y sus reconfiguraciones políticas y sociales, van acompañados de una serie de contestaciones que otorgan más importancia a unos actores u otros, modificando la jerarquía en la que se disponen las escalas. El asumir estos fenómenos de empoderamiento y desempoderamiento, implica entender la dimensión vertical del espacio no de una manera estática, sino atravesada por una continua (des)territorialización que convierte a las escalas en un conjunto de redes interconectadas por las relaciones de poder. Por ello, resulta de interés dar prioridad a un prisma "glocal" (Swyngeoduw, 1997; p. 124). El estudio del metabolismo ecosocial no sería posible sin tener en consideración cómo los cambios en la producción de la naturaleza, van ligados a la necesidad de nuevas configuraciones espaciales, generando nuevas formas de relacionarse para reproducir la distribución vigente del poder en lo que tiene que ver con el acceso y la valoración de los recursos naturales (Swyngedouw, 2006). A diferencia de la "trampa local", en la que tradicionalmente se habría caído en los estudios de los conflictos ambientales, esta daba por hecho que las decisiones, organizaciones y conflictos de una escala no eran producto de una serie de fenómenos que habían tenido lugar en otra instancia (Brown y Purcell, 2005).

En virtud de todo ello, el análisis del conflicto se dividirá en tres bloques: En el primero, se recogerá una síntesis de la dialéctica espacio-temporal, en lo que a la producción del propio espacio del conflicto y sus relaciones se refiere. Tras lo cual, en los dos siguientes bloques, se analizarán por separado las distintas posiciones que se dan: la de los defensores de la construcción y los detractores, considerando cuáles son sus prácticas y discursos, para la continuidad de las relaciones de poder actuales o a su subversión.

\section{Recorrido espacio-temporal del conflicto de Belo Monte}

Analizar el conflicto socioambiental de Belo Monte, pasa por tener en cuenta que no experimenta un desarrollo lineal. Para encontrar estos continuos cambios en el avance del proyecto, hay que remontarse hasta 1975. Bajo la dictadura de Geisel se iniciaron los estudios para un posible aprovechamiento del potencial hidroeléctrico del río Xingú. Desde ese momento hasta la actualidad hay que diferenciar entre tres actores institucionales claves en el avance de la construcción del complejo hidroeléctrico: Eletrobras, Eletronorte y Norte Energía. La primera es la empresa estatal fundada en 1962, dependiente del Ministerio de Minas y Energía, responsable en un principio de toda la gestión del sector eléctrico en el país, aunque haya ido perdiendo competencias en el paso del tiempo por otras entidades como la Agencia Nacional de la Energía Eléctrica (ANEEL). La segunda es una filial regional de la primera, creada en 1973, con el fin principal de establecer proyectos concretos capaces de aprovechar al máximo el potencial hidroeléctrico amazónico (Centro da Memória da Eletricidade no Brasil, 2004) y que a finales de los años ochenta —debido al retraso en el desarrollo de estos proyectos y al déficit en las cuentas del estado- se reconfigura mediante la entrada de capital extranjero. Norte Energía por su parte es la sociedad anónima en la que participa Eletronorte, así como otros múltiples inversores de capital privado nacional y extranjero, encargada de la construcción de la represa de Belo Monte desde 2010.

Volviendo a los inicios de la puesta en marcha del proyecto, hay que apuntar que el de Belo 
Monte no era un caso aislado, estaba insertado en las líneas políticas de desarrollo económico para el país basadas en la idea de adquisición de soberanía nacional mediante la autosuficiencia energética, aunque tenía más relación la búsqueda de mercados globales (Fernandes, 2005). La propuesta para el Xingú fue denominada como la del Complejo Hidroeléctrico de Altamira y englobaba dos represas principales: la de Babaquara (Altamira) y la de Kararaô (Belo Monte). Concretamente Kararaô debía de estar en funcionamiento entorno al 2000 y Babaquara en el 2005. Para lograr dicho objetivo, en una primera instancia se solicitó un informe al Consorcio Nacional de Ingenieros Consultores, acerca del impacto ambiental que causarían. Un año después, el Departamento Nacional de Aguas y Energía Eléctrica, aprobó la puesta en marcha de la construcción, tras la revisión de las valoraciones recogidas en dichos informes. En ese mismo año surgió la primera cortapisa para la ejecución, ya que la recién promulgada Constitución Federal, reconocía del derecho originario de los pueblos indígenas con respecto a los recursos hidráulicos, abriéndose la necesidad de consultarles y obtener la aprobación del Congreso.

Pese a esta paralización del avance del proyecto, en 1989, se suceden una serie de movilizaciones en el núcleo urbano de Altamira, que derivan en el Primer Encuentro de Pueblos Indígenas del río Xingú, con el horizonte de conseguir el derecho a la participación para la paralización del proyecto inicial. Estas, aunque no hicieron efectivo el derecho a la participación de los pueblos indígenas, supusieron la creación de un panel de expertos para revisar los informes de impacto ambiental. En 1995, por parte del Departamento Nacional de Aguas y Energía Eléctrica surgió una propuesta para una menor inundación, pasando de un área de $1225 \mathrm{~km}^{2}$ a otra de 440 km² (Hall y Brandford, 20 I2). Esta reelaboración en el año 2002, buscaba obtener una mayor aprobación tanto por parte de los movimientos sociales ecologistas como de las comunidades locales. Los cambios más significativos tenían que ver con pasar de seis represas principales (Jarina, Kokraimoro, Ipixuna, Babaquara, Kararaô y otra sobre un afluente del Xingú, el Iriri) a sólo tres (Pimentel, Belo Monte y Bela Vista). De esta manera, aunque se disminuía la altura de la caída del agua obteniendo un menor rendimiento, se obtendría un buen rendimiento gracias a los canales de inundación, que llevarían el cauce hacia la curva de la presa de Pimentel.

Figura I.I.Área de inundación antes y después de la revisión del Informe de Impacto Ambiental y de la nueva propuesta de 1995

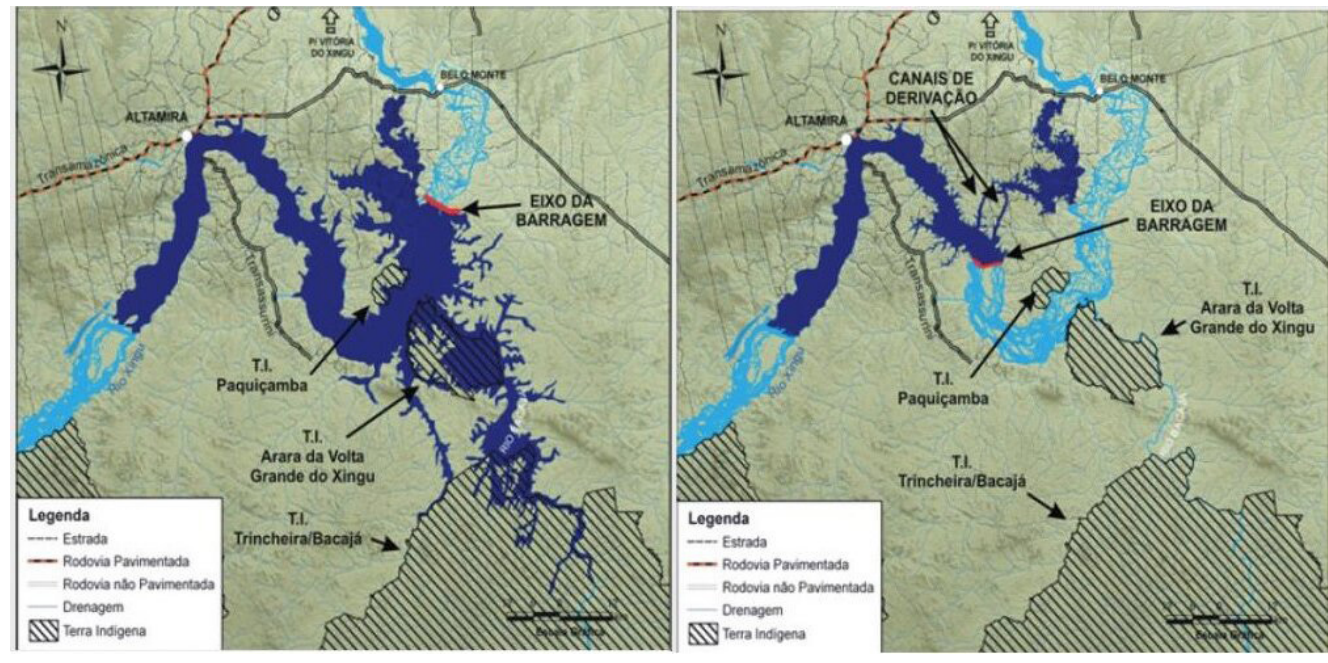

Fuente: Ministerio de Minas y Energía 
Figura I.2 Distribución en las represas en el complejo hidroeléctrico mediante la propuesta final

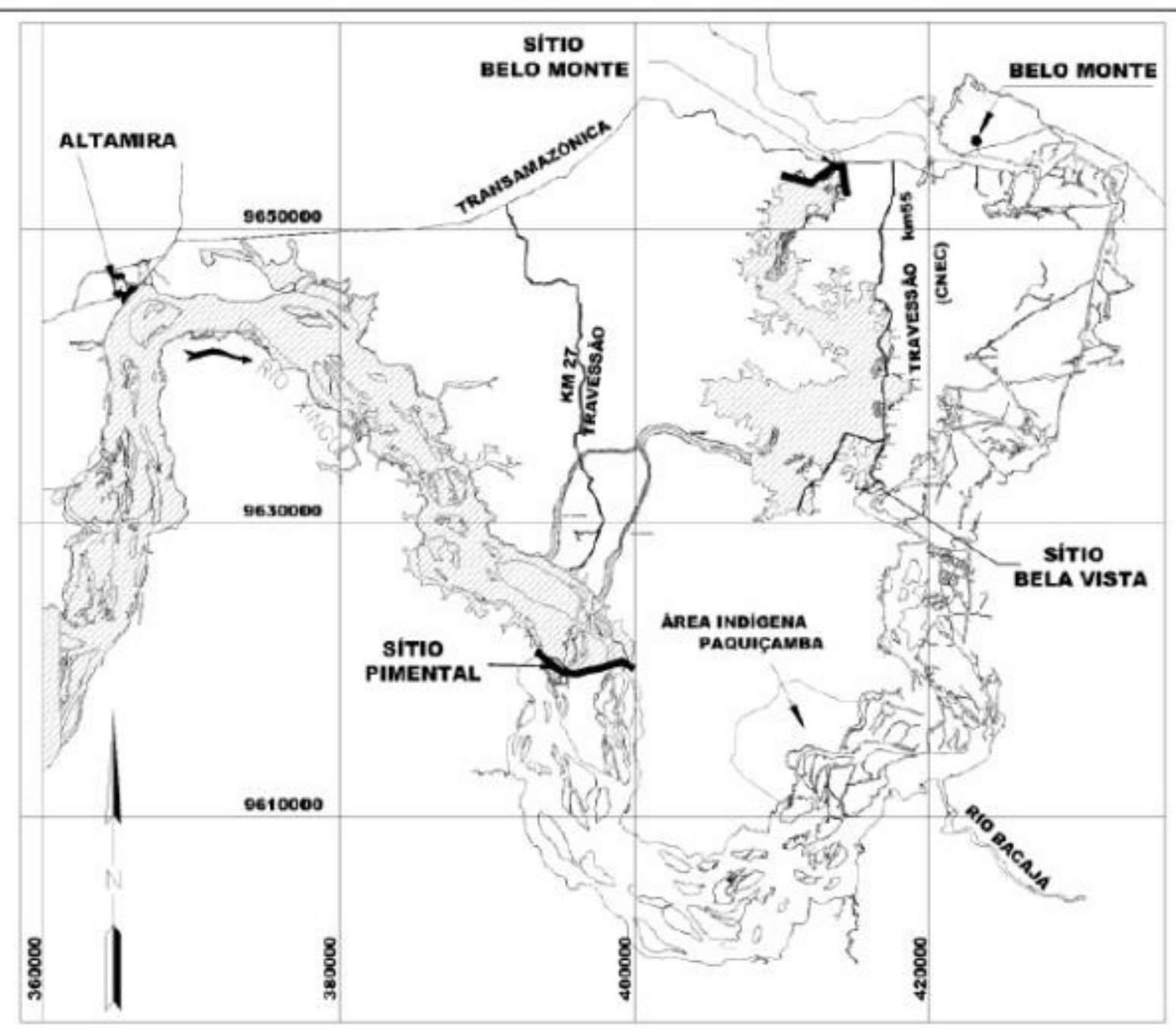

Fuente: Ministerio de Minas y Energía

En 2004, ya durante el nuevo gobierno del Partido de los Trabajadores (PT), al frente de Luis Ignacio "Lula" da Silva, se vuelve a detener el avance. En esta ocasión la razón fue la detección de varias fallas legales por parte del Ministerio Público Federal.Ya en 2007 se retomó el proyecto, celebrando un conjunto de talleres de participación social a lo largo de las poblaciones afectadas. Aunque por parte de del Ministerio de Minas y Energía y Eletrobras, estos se realizaban bajo la intención de servir como consultas a las comunidades indígenas, para la Fundación Nacional del Indio (FUNAl) estos talleres no cumplían los requisitos mínimos ni de información ni participación para contar como tal (FUNAI, 2009). En el 2008, se inició una nueva ola de movilizaciones y protestas en contra el proyecto, ya que además se había hecho público que el Banco Nacional

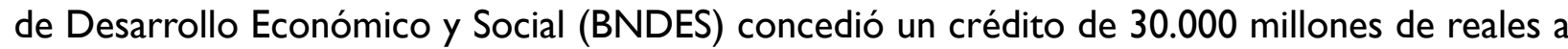
Eletronorte, aún a pesar del incumplimiento de los criterios sociales que debía incorporar.

Para 2008, el Instituto Brasileño de Medio Ambiente y Recursos Naturales Renovables (IBAMA) otorgó una licencia provisional. Pero de nuevo se iba a ordenar una paralización, esta vez a causa de un recurso de inconstitucionalidad presentado ante la Fiscalía General Federal, 
basándose en la violación que se hacía con respecto a los derechos de las comunidades indígenas en el uso del suelo. En agosto, Lula da Silva firmó el contrato con Norte Energía, aunque aún hacía falta una licencia medioambiental por parte de IBAMA. Esta se concedió parcialmente, aunque no cumplía el total de las cuarenta y una acciones requeridas para mitigar el impacto ambiental, autorizándose sólo algunos avances (Hall y Brandford, 20I 2; p. I I).

Cuatro años después, el IBAMA terminó concediendo la licencia para continuar durante cinco años con el desarrollo del proyecto, aún a pesar de la oposición de múltiples técnicos implicados (Fainguelernt, 2013), debido al incumplimiento de doce de los puntos en materia medioambiental y de indemnización a las comunidades locales; no obstante, se alcanzó un acuerdo con la FUNAI. En 20I I la Comisión Interamericana de Derechos Humanos de la Organización de Estados Americanos solicitó la paralización del proyecto, alegando la ausencia de un consentimiento libre e informado, por parte de los pueblos originarios. La por entonces presidenta Dilma Rousseff mostró su rechazo a esta reclamación por parte de esta institución supranacional, llegando a suspender los pagos con los que el país tenía que contribuir como miembro de esta organización. La orden judicial más reciente y de mayor importancia, que ha vuelto a detener la construcción de Belo Monte, tuvo lugar en 2017, en relación con las indemnizaciones por daños materiales que se tenían que efectuar por parte de Eletronorte a las poblaciones afectadas, acordando una reubicación lo más próxima posible a la localización original. Al no haber consensuado esta decisión con la parte afectada, el juzgado encargado del fallo consideró necesaria la paralización hasta alcanzar un nuevo acuerdo (Klein, 20I5).

\section{Actores hegemónicos: prácticas, discursos y relaciones de dominación}

Un elemento indispensable para comprender las relaciones entre los actores que se muestran favorables al desarrollo del complejo hidroeléctrico es el carácter global que adquiere este conflicto hidrosocial. No en el sentido de que se desdibuje del todo la idiosincrasia de este, sino que las relaciones de poder se ven influenciadas tanto por las alteraciones en los ciclos de acumulación a nivel transnacional, y las consecuencias que eso acarrea en las relaciones productivas en la escala nacional, como con los discursos que se filtran para legitimar este proyecto.

En lo que a los ciclos de acumulación-expansión se refiere (Wallerstein, 2004), hace falta recordar la mayor especialización que ha ido adquiriendo Brasil en la producción de energía hidroeléctrica para superar la crisis global de acumulación de finales de los años setenta, buscando nuevos mercados a través de los que llevar a cabo una realización del plusvalor para iniciar así un nuevo ciclo de expansión (Harvey, 2007b). A esto se suma el creciente peso de la industria del aluminio de China, o más específicamente de sus distintas compañías encargadas de la transformación química de la alúmina (óxido de aluminio) en aluminio, a través de la energía hidroeléctrica barata que puede producir potencialmente Brasil (Fearnside, 2016), profundizando este rol rentista en cooperación con las principales constructoras de brasileñas (Camargo Correa y el conglomerado de Norte Energía).

De este modo, las divisas de estas actividades, cierran un triángulo por el cual el propio estado reinvierte parte de estas en la licitación de nuevas infraestructuras, bien en forma de más presas, carreteras, puertos, aeropuertos, telecomunicaciones etc, desarrolladas por las 
mismas constructoras u otras empresas de capital público/privado. Buena muestra de ello es la propia composición de Norte Energía, dentro de la cual la mitad del accionariado es público (Eletrobras, Eletronorte y Chesf) y la otra mitad privada, a través de compañías como Light, Cemig e lberdrola, entre otras. La creación de este conglomerado para construir la represa, gracias a la descentralización administrativa regional para la gestión hidroeléctrica llevada a cabo en las décadas pasadas (Centro da Memória da Eletricidade no Brasil, 1996) es un mecanismo que ha posibilitado la entrada de capital privado desde la escala global a la propia escala local.

Todas estas infraestructuras conforman un conjunto de nuevos enclaves que alteran el plano económico, social, político y medioambiental, mediante una reestructuración territorial, que actúa como un vector más en los procesos de integración regional y los flujos globales de capital (Vainer, 2007). De esta manera se facilita la actividad de las empresas chinas o extranjeras que importan la energía generada, así como el mantenimiento de las relaciones comerciales con estas, obteniendo más rentas, volviéndose a repetir el mismo. Se puede apreciar este hecho, en cómo a nivel regional ya no se impulsa sólo el desarrollo de represas hidroeléctricas, sino que se va más allá en la especialización de producción de energía, mediante la interconexión de las centrales termoeléctricas con los gaseoductos que transportan el gas desde Bolivia, abaratando el proceso (Saraiva de Paula, 2005).

\section{Gráfico I. Producción de energía total, energía eléctrica y energía hidroeléctrica en Brasil desde 1970 hasta 1990}

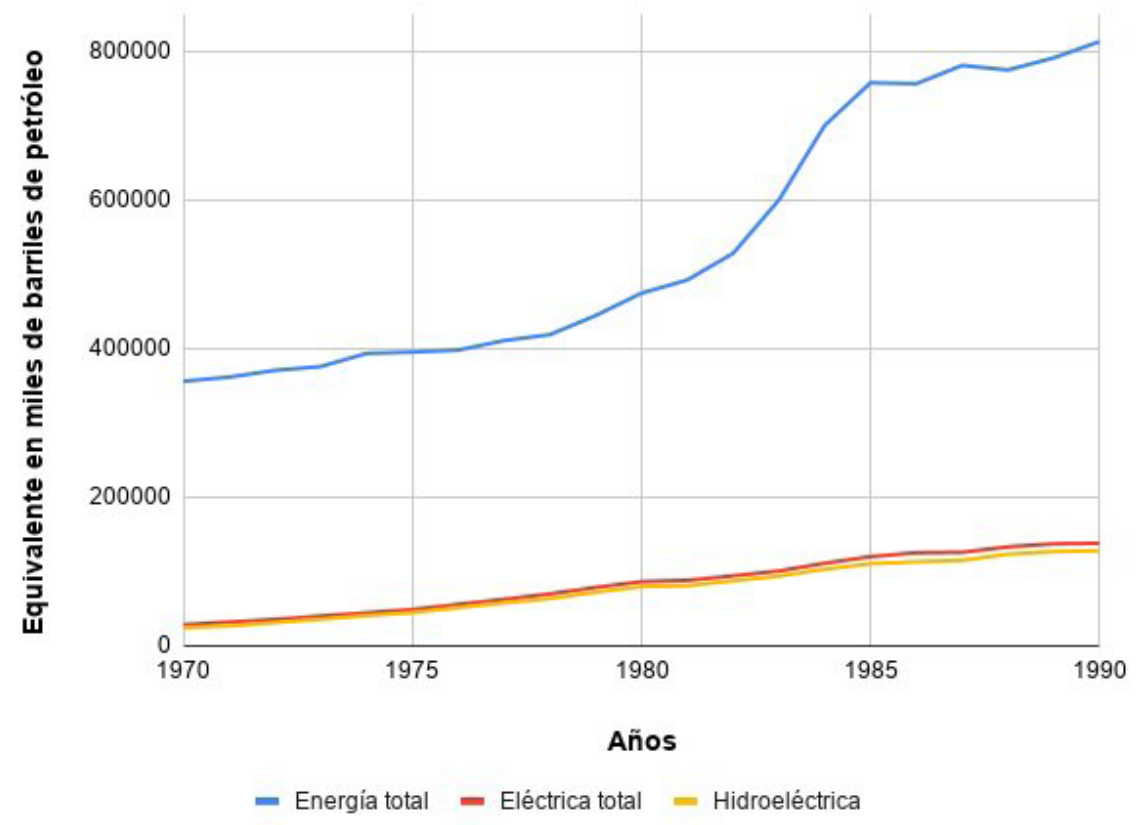

Fuente: CEPALSTAT

Aún a pesar de la desterritorialización cada vez mayor del ciclo hidrosocial por su mayor carácter global, el estado, y sus distintas instituciones, como actor sigue siendo de gran influencia. Es necesario entrar a considerar que, en el caso de este conflicto ambiental -así como en otros dentro del país de manera reciente (de Souza Porto, 2018)_, las estructuras del estado no son 
neutras, en tanto que el acceso a él por parte de una formación o un grupo político, no permite una libertad total a la hora de llevar a cabo una serie de acciones o prácticas concretas, que hasta cierto punto desborden unas relaciones de poder particulares y previamente establecidas. El Estado brasileño, como estado-nación moderno, habría operado como estructura en el plano de integración y de producto de las correlaciones de poder a nivel social (Poulantzas, 2000; Jessop, 2007).

Integrando en el plano político clases sociales subalternas que durante los años 80 del siglo pasado no lo estaban (Boito y Berringer, 20I3), pero que con el triunfo de Lula y el PT empezaron a experimentar esta incorporación. Y a la vez, siendo un producto de las correlaciones de poder, en tanto que en el periodo de transición de los primeros gobiernos elegidos democráticamente, así como tras el proceso constituyente de 1988, hay que tener en cuenta que el poder de la burguesía nacional y los grandes terratenientes, entre otras élites, se mantiene en las estructuras políticas del estado, incluyendo las legislaturas del propio PT (Anderson, 2019).

El elemento que mejor refleja esta dimensión del estado como herramienta para la reproducción de las relaciones productivas que se dan en un país de la periferia extractivista es el cambio de posición que ha ido experimentando el PT a lo largo de los años con respecto a la ejecución de Belo Monte. Si bien a partir de 1989, cuando la cuestión adquirió una gran relevancia en la agenda política de Brasil, fue el propio PT, con Lula da Silva a la cabeza, quien consiguió capitalizar el bloque en contra de esta infraestructura, frente a Fernando Collor de Melo, que era el candidato a la Presidencia. Finalmente, en 2004 cambió de posicionamiento y declaró este proyecto como una prioridad (Fainguelernt, 2013) convirtiéndolo en el eje angular del Plan de Crecimiento Acelerado, por el cual estas grandes infraestructuras del sector energético iban a ser centrales en la nueva legislatura del PT. Durante la primera legislatura de Dilma Rousseff se llegará a afirmar que

"El esquema hidroeléctrico de Belo Monte debe verse como un factor importante en el desarrollo socioeconómico regional y nacional, con impactos positivos en capacidad nacional de generación de energía y, en consecuencia, sobre la calidad de vida de los brasileños" (República Federativa do Brasil, 20I I; p. 16).

Si durante los años ochenta y noventa, la principal retórica que se empleaba desde el estado para justificar este proyecto era el de la soberanía nacional, durante los gobiernos del PT, la legitimación se va a buscar en el discurso del desarrollo sostenible (Sachs, 1997); dando muestra de cómo este conflicto se ha visto influenciado por múltiples aspectos más allá de la escala nacional. Cómo analiza Lorena Fleury (2013) en las distintas prácticas discursivas de las instituciones del estado, hay una insistencia constante en el carácter vital de este proyecto para combatir las bolsas de pobreza existentes en la región, incorporando la perspectiva de la sostenibilidad y de la mitigación de los impactos ambientales.

Dentro de este marco que se establece acerca de la sostenibilidad del desarrollo, habría que tener en cuenta también los propios actores que pertenecen a esta y que establecen una 
relación de colaboración para llevar a cabo la construcción de la presa, como es el caso del Banco Mundial (BM) y la Comisión Mundial de Presas (CMP), que jugaron un importante papel en la financiación del proyecto. Por ejemplo, a través de informes que emitieron en el 1997 (IUCN, 1997) y el 2000 (World Commission on Dams, 2000), recogieron la necesidad de incorporar nuevas consideraciones a las indemnizaciones que se tenían que realizar.

\section{Actores subalternos: prácticas, discursos y relaciones de resistencia}

El principal rasgo por el que se va a caracterizar el bloque de todos aquellos que se oponen a la construcción del Complejo Hidroeléctrico de Belo Monte va a ser la contestación a lo que se considera como desarrollo. Para las comunidades indígenas, ribereñas y campesinas que habitan las tierras próximas a la cuenca del Xingú en Altamira, el proyecto como tal se opone a la significación que ellos le otorgan al desarrollo en dos planos: en lo que tiene que ver en cuanto a la modificación de sus relaciones de producción en tanto que el río es el medio para obtener muchos de los bienes gracias a los cuales luego poder comerciar y reproducir sus comunidades. Al mismo tiempo, espacialmente la represa representa los intereses de las grandes ciudades del país, contrarias a las necesidades de desarrollo local (Fleury, 20l4).

Por otro lado, los actores de la escala global y los movimientos sociales locales que intervienen, como pueden ser el Movimiento de PersonasAfectadas por las Represas, el Movimiento para el Desarrollo del eje Transamazónico y el Xingú, el Consejo Misionero Indígena, la Comisión Pro-Indio de Sao Paulo, la Red Internacional de Ríos, Greenpeace o Defensa Ambiental; plantean que lo que el gobierno y los actores que se posicionan a favor, no lo hacen por un desarrollo sostenible, sino para buscar nuevas fuentes de energía ante la mayor demanda externa del mercado y limitando el desarrollo al crecimiento económico. Podría afirmarse que estos actores buscan una disputa del sentido de desarrollo sostenible, manteniendo una tensión entre su carácter más cosmopolita en lo que tiene que en el plano medioambiental y otra más local en lo que tiene que ver con el mantenimiento de la identidad local y sus modos de vida.

Aún a pesar de estas conceptualizaciones tan dispares, entre actores tan heterogéneos se van a tender una serie de alianzas que van a resultar fructíferas, más allá de la escala nacional, y además se va a poder modificar y paralizar en muy distintas ocasiones como ya se ha señalado en los apartados anteriores. En este caso concreto, se produce un intercambio de los roles, ya que los movimientos sociales locales y en parte las comunidades originarias, emplean tanto el Informe de Impacto Ambiental, como los cambios legislativos que tienen lugar tras la promulgación de la Constitución Federal de 1988, para visibilizar las consecuencias medioambientales, y el conflicto de interés en cuanto al derecho a acceder a los distintos recursos, para así poder dilatar tanto la licitación como el avance del proyecto. Mientras que los movimientos sociales transnacionales y las Organizaciones No Gubernamentales (ONG) se desempeñaron en la visibilización de la trascendencia del conflicto, haciendo que en última instancia llegaran a intervenir incluso el propio BM y la CMP.

Otro elemento a tener en cuenta en el análisis de la reconfiguración de las relaciones es la introducción de una valoración distinta, ante los impactos que la represa tiene, intentando ir más allá del carácter marginalista y compensatorio. Al igual que los movimientos sociales y las 
comunidades otorgan distintos sentidos a la cuestión de lo que es el desarrollo, en el caso de valorar impactos, ocurre algo similar. Aunque uno de los ejes retóricos más empleados por parte de los actores que están a favor sea el hecho de que se trata de una fuente de energía renovable y un motor para el desarrollo de una economía verde en el país, se busca refutar en otras dimensiones las repercusiones ambientales que tiene.

En primer lugar, por la pérdida de biodiversidad ligada a la inundación en los límites de la presa, ya que esta impide la supervivencia de determinadas especies, modificando las tasas de biomasa que hay río arriba, afectando especies del Xingú que dependen de la variabilidad de estas ratios. Después estaría la producción de metano $\left(\mathrm{CH}_{4}\right)$. Aunque las emisiones de dióxido de carbono $\left(\mathrm{CO}_{2}\right)$ son las que se han considerado en el IIA, la represa apenas genera un volumen considerable en relación con su superficie y a la cantidad de vatios generados. Pero sí que habría una ingente liberación de $\mathrm{CH}_{4}$ al entorno, como consecuencia de la actividad de las turbinas, siendo hasta $2 \mathrm{I}$ veces más nocivo que el $\mathrm{CO}_{2}$ (Fearnside, 2006).

Con respecto a las diversas comunidades locales, estas de nuevo van a reivindicar más el papel que tiene el río y el acceso a sus recursos hídricos en la reproducción de sus relaciones productivas, no sin que los movimientos sociales también pongan en consideración esta dimensión. Concretamente en el caso de los campesinos que tienen en la zona de la represa sus cultivos, se verían desplazados por la extensión de los distintos canales y zonas de inundación, limitando al mismo tiempo la capacidad productiva, trasladándose a territorios de menor fertilidad. Los ribereños, por su parte, se ven doblemente damnificados, ya que los reservorios que se creasen a lo largo del complejo alterarían los ciclos de inundación-sequía que establecen sus ritmos de trabajo a lo largo del año, debido a que condicionan y posibilitan el crecimiento de determinadas especies de peces con las que comercian.Al mismo tiempo, la destrucción de los cauces naturales del río rompe su principal vía de comunicación con Altamira, impidiendo así la misma actividad comercial. En tercer lugar, los perjuicios que tendrían lugar serían similares en lo que el Xingú a nivel de movilidad supone, no tanto en la pesca porque no son tan dependientes, pero sí para el comercio de productos como las castañas y las andirobas, además de otras consecuencias como dificultar el acceso a servicios educativos y sanitarios.

Toda esta reconfiguración social, iría acompañada de una reordenación espacial de la localidad a través de las nuevas posiciones a las que se verían desplazados estos actores subalternos. La aparición de los ribereños y los campesinos en la cuenca del Xingú, fue fruto del fenómeno de colonización y el asentamiento del poder hacendal a lo largo de toda la Amazonía a partir del siglo XVI, no sólo en la parte brasileña (García Linera, 20l3) conviviendo junto a las comunidades indígenas y dedicándose originalmente sobre todo a la explotación del caucho y la castaña. Tras la creación de la carretera transamazónica BR-230, la ciudad de Altamira como punto intermedio entre esta infraestructura y el Xingú, experimentó un crecimiento poblacional, convirtiéndose en un importante foco para la actividad económica y la provisión de nuevos servicios. La ejecución del proyecto de Belo Monte, supondría una continuación de este proceso de urbanización iniciado años atrás, continuando con el incremento demográfico debido al desplazamiento de nuevos profesionales y técnicos a la ciudad para posibilitar la actividad del complejo hidroeléctrico y la reubicación a la que se verían forzados los ribereños, campesinos e indígenas en las favelas, como consecuencia de ser el espacio más próximo tras la desaparición de sus hogares y el único 
accesible dados sus recursos materiales (Randell, 2016).

\section{Conclusión}

A modo de síntesis, y en base a las ideas que han ido emergiendo a lo largo del texto, se pueden extraer las siguientes conclusiones, en el plano concreto de este caso, en uno más abstracto con los ciclos hidrosociales y a nivel de la utilidad del marco teórico propuesto:

- En el caso de Belo Monte, o en otros similares que pudieran tener lugar en el Sur Global, la construcción de represas supone una reconfiguración de las relaciones sociales dadas en tanto que para algunos actores (constructoras, firmas energéticas, empresas trasnacionales...) propios del modo de producción capitalista, los grandes caudales de ríos como el Xingú u otros similares en la región, adquieren valor de uso en tanto que si se generan las infraestructuras adecuadas pueden generar una energía eléctrica cada vez más demandada, lo cual se traduce en nuevos nichos de plusvalor. Para las comunidades locales, el acceso a este adquiere un valor de uso distinto ya que la extracción de sus recursos y el emplearlo como vía de comunicación para el comercio, es lo que permite el mantenimiento de sus relaciones productivas. Este cambio de las relaciones sociales en la escala local es consustancial a la nueva fragmentación territorial que emerge ante un proyecto de tal envergadura e inversión, convirtiéndolo en un enclave que posibilita una mayor integración regional y nacional de la Amazonía brasileña. El conflicto hidrosocial entorno a la construcción de la presa sería por tanto consecuencia de un ejercicio de resistencia por parte de los actores subalternos del territorio ante el intento de establecer nuevas relaciones de poder.

- La crisis de finales de los setenta habría impulsado estos macroproyectos extractivistas de cara a una realización del plusvalor acumulado a lo largo del espacio y el tiempo (Harvey, 2007b), obteniendo una mediación por parte de actores como el estado. Su carácter no neutro, fruto de la correlación de fuerzas de clase, va a poner en marcha procedimientos legislativos y ejecutivos para hacerlos viables, transformando de este modo la escala local, pasando de estar sostenida por estructuras sociales rurales a otras nuevas con un carácter mucho más urbano. Esta dimensión del rol del estado como institución dentro del conflicto ambiental se puede observar en el papel de instituciones como el IBAMA y las empresas hidroeléctricas estatales. Por parte del IBAMA, en lo referente a los contrastes y polémicas existentes entre los informes, la concesión de las licencias en base a los criterios exigidos y los posicionamientos de los técnicos. Mientras, en el caso de las segundas, su fraccionamiento en la escala regional posibilitó la capitalización mediante inversores extranjeros y conglomerados, como con Norte Energía, a través de los cuales el carácter privado de estas infraestructuras se ve incrementado, accediendo a nuevos valores de cambio.

- Categorías como la de escala, resultan ser de una importante validez para analizar conflictos hidrosociales similares, ya que aportan un marco que tiene en consideración la influencia en estos procesos por parte de actores de diversas procedencias espaciales, mediante sus prácticas y sus discursos, así como su movilidad no sólo de manera horizontal sino también vertical. Por otro lado, ponen el foco en cómo los cambios entre la naturaleza y la sociedad no pueden comprenderse al margen de las múltiples relaciones que los atraviesan y del ejercicio de poder que se realiza a través de estas. Lo mismo sucede con la producción 
del espacio; sus categorías de prácticas espaciales y representaciones espaciales, sirven para explicar cómo los actores hegemónicos llevan a cabo de manera abstracta y concreta una territorialización del proceso de extensión de determinadas relaciones productivas y mecanismos para la acumulación, así como los actores subalternos llevan a cabo una respuesta de estas mediante los espacios de representación, manteniendo formas de valor intrínsecas a sus relaciones sociales, tanto productivas como reproductivas.

- En lo referido a la aplicación del marco de la producción de la naturaleza, la categoría de "valor" como síntesis dialéctica explica la emergencia del conflicto. Dado el choque entre diferentes "valores" de uso del agua en las diferentes estructuras sociales - de las comunidades locales, por un lado y, por otro, las del estado-nación brasileño-, el valor de cambio, ausente para las comunidades locales dada la ausencia de intercambio y fetichización, se adquiere en tanto que hay una mercantilización propia. Esto hace que se le atribuya al agua una valorización mediante su equivalencia abstracta en el tiempo de trabajo para que ese caudal haga funcionales a las represas. Pese al encaje del elemento de las infraestructuras o enclaves, ligados al complejo hidroeléctrico, para hacer efectivo un tiempo de trabajo socialmente necesario que de valor al agua del Xingú; esta relación se vuelve complicada al tener que considerar el tratamiento que se debería dar al agua como pseudomercancía en la ecología-mundo y su papel rentístico derivados de nuevos procesos y cadenas globales de valor (Prudham, 2007; Andreucci et al., 2017). Teniendo en cuenta esta última condición, aún con las fortalezas que muestra la categoría de valor, sería necesaria una mayor discusión de su aplicación como marco en los conflictos ambientales para pseudomercancías como el agua. Con respecto a las ideas de primera y segunda naturaleza, estas se muestran útiles entendidas como proceso de extensión de las relaciones de producción y las prácticas de acumulación con mediación del estado y otros actores, dentro del cual surgen resistencias relacionadas con la propiedad, la reproducción social, etc. Mientras, la categoría de "condiciones externas" ve más limitada su aplicación, puesto que si en parte explica el avance de infraestructuras y enclaves como modos de integración para la acumulación, su supeditación a crisis de subproducción puede rebajar su utilidad analítica para la coyuntura de un conflicto ambiental.

- En respuesta al tercer objetivo planteado al inicio del artículo, se puede decir que la perspectiva escalar y de la producción del espacio, posibilitan establecer qué conexiones espaciales unen los distintos actores, estructuras y prácticas que influyen en el conflicto de Belo Monte. Así como el marco la producción de la naturaleza lo posibilita parcialmente, necesitando un mayor desarrollo en futuros trabajos. Sin embargo, este enfoque evita que los cambios en los usos y valores ligados a la represa se analicen de manera autónoma, conectándolos en todo momento a las transformaciones en las relaciones de producción, de poder y los ciclos hidrosociales, aportando mayor capacidad explicativa. Aún así, este planteamiento también presenta algunas limitaciones; por ejemplo, no se focaliza tanto en la escala local, y no adquiere un carácter tan antropológico como el de otros trabajos previos (Fearnside, 2006; Bingham, 20 I0; Fleury, 20I4), lo cual, en parte, dificulta el análisis en mayor detalle de la idiosincrasia de los actores pertenecientes a esta escala.

\section{Referencias}

Altvater, E. (2006). ¿Existe un marxismo ecológico? En Boron, A.;Amadeo, J.y González S. (Comp): La teoría marxista 
hoy: problemas y perspectivas. Buenos Aires: CLACSO.

Amin, S. (1972). Underdevelopment and dependence in Black Africa-origins and contemporary forms. The Journal of Modern African Studies, I0 (4), 503-524. DOI: I0.10I7/S0022278X0002280 I

Anderson, P. (2019). Brasil: una excepción (1964-20/9). Madrid:Akal.

Andreucci, D., García-Lamarca, M., Wedekind, J. ySwyngedouw, E. (2017). "Value grabbing”: A political ecology of rent. Capitalism Nature Socialism, 28 (3), 28-47. DOI: 10.1080/I0455752.20 I6. I 278027

Arboleda, M. (2016). Spaces of extraction, metropolitan explosions: planetary urbanization and the commodity boom in Latin America. International Journal of Urban and Regional Research, 40 (I), 96-II2. DOI:I0.1।II/I4682427.12290

Boito, A. y Berringer, T. (20/3). Classes sociais, neodesenvolvimentismo e política externa nos governos Lula e Dilma. Revista de Sociología e Política, 47, 3I-38. Recuperado de: http://https://revistas.ufpr.br/rsp/article/ view/34470/2I 378 (0I/I2/2019)

Briassoulis, H. (2019). Analysis of Land Use Change:Theoretical and Modeling Approaches. Charleston: Regional Research Institute of West Virginia University.

Brown, J. C. y Purcell, M. (2005). There's nothing inherent about scale: political ecology, the local trap, and the politics of development in the Brazilian Amazon. Geoforum, 36 (5), 607-624. DOI:I0.1016/j.geoforum.2004.09.00 I

Burkett, P. (2013). Marxism and ecological economics. Boston:Aakar Books.

Castree, N. (2005). Differential geographies: place, indigenous rights and 'local' resources. Political geography, 23 (2), |33-|67. DOI:10.1016/j.polgeo.2003.09.010

Castree, N. (2008). The production of nature. En Sheppard, E.y T.J. Barnes (Comp.). A companion to economic geography. Oxford: Blackwell Publishing.

Centro da Memória da Eletricidade no Brasil (1996). Notas sobre o racionamento de energia elétrica no Brasil (I9401980). Río de Janeiro: Centro da Memória da Eletricidade no Brasil.

Centro da memória da eletricidade no Brasil (2004). Eletronorte 30 anos de pura energia brasileira. Río de Janeiro: Centro da Memória da Eletricidade no Brasil.

Corrêa, SRM (2016). Neodevelopment y conflictos sociales: el caso de la presa de Belo Monte. Nuevos cuadernos NAEA , 19 (3), 233-254. DOI: I0.580I/ncn.v19i3.26I0

Daly, H. E. (1989). Economía, ecología y ética. Ciudad de México: Fondo de Cultura Económica.

De Souza Porto, M. F. (2018). ¿Desarrollo para qué y para quién? La experiencia del Mapa de Conflictos relacionados con la injusticia ambiental y la salud en Brasil. Commons: Revista de Comunicación y Ciudadanía Digital, 7 (I), 193-22I. Recuperado de: https://revistas.uca.es/pre/index.php/cayp/article/view/4067 (01/I2/2019)

Dos Santos, R. S. P. y Milanez, B. (20I3). Neoextrativismo no Brasil? Uma análise da proposta do novo marco legal da mineração. Revista Pós Ciências Sociais, 10 (19), I | 9-|48. Recuperado de: http://www.periodicoseletronicos. ufma.br/index.php/rpcsoc/article/view/I940 (0I/I2/2019).

Dutt,A. K. y Krishna, D.A. (1 990). Growth, distribution and uneven development. Cambridge: Cambridge University Press.

Loftus, A. y Ekers, M. (2013). Revitalizing the production of nature thesis: A Gramscian turn? Progress in Human Geography, 37 (2), 234-252. DOI: I0.I I 77/0309 I325 I 244883 I

Fainguelernt, M. (20I3). Belo Monte: Reflexiones críticas sobre la trayectoria histórica del proyecto de la hidroeléctrica y los escollos de las licencias ambientales en el Brasil. Bienes comunes. Saqueo y resistencias, |3|-|4|. Recuperado de: http://pim.udelar.edu.uy/wp-content/uploads/sites/I4/20I7/03/Revista-Contrapunto-2.pdf $(01 / 12 / 2019)$

Fearnside, P. M. (2006). Dams in the Amazon: Belo Monte and Brazil's hydroelectric development of the Xingu River Basin. Environmental management, 38 (I), I6. DOI: 10.1007/s00267-005-0I I 3-6

Fearnside, P. M. (2016). Environmental and social impacts of hydroelectric dams in Brazilian Amazonia: Implications for the aluminum industry. World Development, 77, 48-65. DOI:I0.1016/j.worlddev.2015.08.015

Fearnside, PM. (2017). Belo Monte:Actores y argumentos en la lucha por la represa amazónica más controvertida de Brasil. DIE ERDE - Revista de la Sociedad Geográfica de Berlín, I48 (I), I4-26. Recuperado de: https://revista.fct. unesp.br/index.php/nera/article/view/569I (0I//2/2019).

Fernandes, F.A. (2005). Revolução Burguesa no Brasil: ensaio de interpretação sociológica. São Paulo: Globo.

Fleury, LC. (2013). Conflicto ambiental y cosmopolítico en la Amazonía brasileña: la construcción de la central hidroeléctrica Belo Monte en perspectiva (Tesis Doctoral). Universidad Porto Alegre. Recuperado de: https://lume.ufrgs.br/ handle/I0I83/90I84 (0I/I2/2019).

Fleury, LC. (2014). Disputas cosmopolíticas y conflictos ambientales en la Amazonía brasileña, desde la construcción de la Central Hidroeléctrica Belo Monte. Actas REACT-Reunión de Antropología de la Ciencia y la Tecnología, I (I). Recuperado de: http://ocs.ige.unicamp.br/ojs/index.php/react/article/view/II 92

Frank, A. G. (I97I). Development of underdevelopment. Barcelona:Anagrama.

FUNAI (2009). UHE Belo Monte. Componente Indígena. Informe técnico $n^{\circ} 2$ I. Brasilia: FUNAI. Recuperado de: http:// www.funai.gov.br/index.php/servicos/publicacoes (01/I2/2019).

García Linera,A. (20I3). Geopolítica de la Amazonia. La Paz:Vicepresidencia del Estado Plurinacional de Bolivia.

Hall,A.y Branford, S. (20I2). Development, dams and Dilma: the saga of Belo Monte. Critical Sociology, 38 (6), 85 I-862. DOI: I0.II77/08969205/24407/2

Harvey, D. (2007a). Breve historia del neoliberalismo. Madrid: Ediciones Akal.

Harvey, D. (2007b). Espacios del capital. Hacia una geografia crítica. Madrid:Akal. 
Heynen, N., Perkins, H. A., y Roy, P. (2006). The political ecology of uneven urban green space:The impact of political economy on race and ethnicity in producing environmental inequality in Milwaukee. Urban Affairs Review, 42 (I), 3-25. DOI: I0.I I77/I078087406290729

Hughes, J. (2000). Ecology and historical materialism. Cambridge: Cambridge University Press.

Issberner, L. R. y Léna, P. (20I7). Brazil in the anthropocene: conflicts between predatory development and environmental policies. Nueva York:Taylor \& Francis.

Jessop, B. (2007). State power. Cambridge: Polity Press.

Kelly, P. F. (1999). The geographies and politics of globalization. Progress in Human Geography, 23 (3), 379-400. DOI: I0.1I77/0309|3259902300303

Kingsford, R.T. (2000). Ecological impacts of dams, water diversions and river management on floodplain wetlands in Australia. Austral Ecology, 25 (2), I09-I27. DOI: I0.I046/j.I442-9993.2000.01036.x

Klein, P.T. (2015). Engaging the Brazilian state: the Belo Monte dam and the struggle for political voice. The Journal of Peasant Studies, 42 (6), I I37-I I56. DOI: 10.1080/03066 I50.2014.9917I9

Lefebvre, H. (1991). The production of space. Oxford: Blackwell.

Marston, S. A. (2000). The social construction of scale. Progress in human geography, 24 (2), $219-242$. DOI:I0.1।91/0309|3200674086272

Martínez Alier, J., y Jusmet, J. R. (20I5). Economía ecológica y política ambiental. Ciudad de México: Fondo de Cultura Económica.

McKibben, B. (1989). The end of nature. Nueva York: Random House Incorporated.

Moore, J.W. (20II). Transcending the metabolic rift: a theory of crises in the capitalist world-ecology. The Journal of Peasant Studies, 38 (I), I-46. DOI: I0.1080/03066I50.2010.538579

O’Connor, J. (200I). Causas naturales: ensayos de marxismo ecológico. Ciudad de México: Siglo XXI.

Pase, H. L., Rocha, H. J. D., Santos, E. R. D. y Patella, A. P. D. (2016). The sociopolitical conflict in hydroelectric enterprises. Ambiente \& Sociedade, I9 (2), 45-66. DOI: I0.I590/I809-4422ASOCI 35480VI9220I6

Peet, R. y Watts, M. (2004). Liberation ecologies: environment, development and social movements. Nueva York: Routledge.

Peters, I. (20I7). Cohesion and Fragmentation in Social Movements: How Frames and Identities Shape the Belo Monte Conflict. Berlín: Springer.

Poulantzas, N.A. (2000). State, power, socialism. Londres:Verso.

Prudham, S. (2007). The fictions of autonomous invention: accumulation by dispossession, commodification and life patents in Canada. Antipode, 39 (3), 406-429. DOI: I 0. I I I I/j. I467-8330.2007.00533.x

Ramos, A. M. y Alves, H. P. (2018). Socio-economic and environmental conflict over the construction of Belo Monte Hydroelectric Power Plant. Desenvolvimento e meio ambiente, 46, I74- I96. DOI: 10.5380/dma.v46i0.50248

Randell, H. (2016). Structure and agency in development-induced forced migration:The case of Brazil's Belo Monte Dam. Population and environment, 37 (3), 265-287. DOI: I0. I007/s I I I I I-0 I5-0245-4

Redclift, M. (|99|). The multiple dimensions of sustainable development. Geography, 36-42. Recuperado de: https:// www.jstor.org/stable/405720I8 (0I/I2/2019)

República Federativa do Brasil (20I I). Comunidades Tradicionais da Bacia do Rio Xingu, Pará. Informações do Estado Brasileiro, CIDH-MC-382-I0. Brasília. Recuperado de: https://documentacao.socioambiental.org/noticias/ anexo_noticia/19927_20110517_104210.pdf (01/12/2019).

Riethof, M. (20I7). The international human rights discourse as a strategic focus in socio-environmental conflicts: the case of hydro-electric dams in Brazil. The International Journal of Human Rights, 21 (4), 482-499. DOI: 10.1080/13642987.2016.1191775

Sachs,W. (1997). Development dictionary, The:A guide to knowledge as power. Londres: Orient Blackswan.

Saraiva de Paula,A. (2005). Análise do projeto Belo Monte e de sua rede de transmissão associada frente às políticas energéticas do Brasil. En Seva Filhó, A. (Org.). Alertas sobre as conseqüências dos projetos hidrelétricos no rio Xingu. Sao Paulo: Red Internacional de Ríos.

Schmidt, A. (20I3). The concept of nature in Marx. Londres:Verso Trade.

Shields, R. (2005). Lefebvre, love and struggle: Spatial dialectics. Londres: Routledge.

Simmel, G. (2010). Conflict and the web of group affiliations. Nueva York: Simon and Schuster.

Simon, J. L. (1997). The ultimate resource. Princeton: Princeton University Press.

Smith, N. (2010). Uneven development: Nature, capital, and the production of space. Georgia: University of Georgia Press.

Soja, E.W. (1989). Postmodern geographies:The reassertion of space in critical social theory. Londres:Verso.

Svampa, M. (2013). Consenso de los Commodities y lenguajes de valoración en América Latina. Fundación Friedrich Ebert; Nueva Sociedad, 4, 30-46. Recuperado de: http://hdl.handle.net/I I336/645 I (0I/I2/20I9).

Swyngedouw, E. (1997). Neither global nor local:'Glocalization' and the politics of scale. En Cox, K. R. (Ed.). Spaces of globalization: reasserting the power of the local (pp. I 15-136). Londres: Guilford Press.

Swyngedouw, E. (2006). Circulations and metabolisms:(hybrid) natures and (cyborg) cities. Science as culture, I5 (2), I05-|2I.DOI: 10.1080/09505430600707970

Swyngedouw, E. (2009). The political economy and political ecology of the hydro $\square$ social cycle.Journal of Contemporary Water Research \& Education, I 42 (I), 56-60. DOI: I0. I I I I/j. I936-704X.2009.00054.x

Swyngedouw, E. y Heynen, N. C. (2003). Urban political ecology, justice and the politics of scale. Antipode, 35 (5), $898-$ 9|8. DOI: I0.I I I I/j. |467-8330.2003.00364.x

Swyngedouw, E., Kaika, M. y Castro, E. (2002). Urban water: a political-ecology perspective. Built Environment, I 24 -I 37. 
Recuperado de: https://www.jstor.org/stable/23288796 (0I/I 2/20I9).

Taylor, P. J. (1982). A materialist framework for political geography. Transactions of the Institute of British Geographers, 7, 15-34. Recuperado de: https://www.jstor.org/stable/62/909 (01//2/2019).

Vainer, CB (2007). Planificación territorial y proyecto nacional: los desafíos de la fragmentación. Revista Brasileña de Estudios Urbanos y Regionales, 9 (I), 9-23. DOI: I0.22296/23 I7-I529.2007v9n I p9

Wallerstein, I. M. (2004). Capitalismo histórico y movimientos antisistémicos: un análisis de sistemas-mundo. Madrid: Ediciones Akal.

Warner, J. F. (2008). Contested hydrohegemony: Hydraulic control and security in Turkey. Water Alternatives, I (2), 27I288. Recuperado de: https://research.wur.nl/en/publications/contested-hydrohegemony-hydraulic-controland-security-in-turkey $(0 \mathrm{I} / \mathrm{/} 2 / 20 / 9)$.

Watts, M. (2015). Now and then: the origins of political ecology and the rebirth of adaptation as a form of thought. En Perreault, T., Bridge, G.y McCarthy, J. (Eds.). The Routledge handbook of political ecology. Londres: Routledge.

Williamson, J. (1993). Democracy and the "Washington consensus". World development, 2 I (8), I329-I336. DOI: $10.1016 / 0305-750 \times(93) 90046-C$ 


\section{RELACIONES INTERNACIONALES}

Revista académica cuatrimestral de publicación electrónica

Grupo de Estudios de Relaciones Internacionales (GERI)

Universidad Autónoma de Madrid, España

https://revistas.uam.es/relacionesinternacionales

ISSN 1699 - 3950

f facebook.com/RelacionesInternacionales

3. twitter.com/RRInternacional 